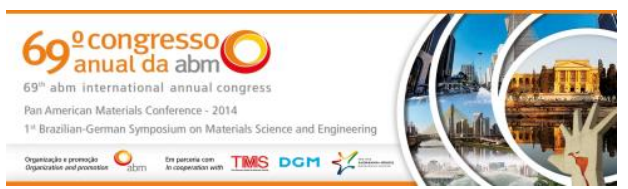

Tema: Soldagem

\title{
CARACTERIZAÇÃO DAS MICROESTRUTURAS E DA RESISTÊNCIA A CORROSÃO DE REVESTIMENTOS DA MISTURA DAS LIGAS DE NÍQUEL AWS ERNiCrMo - 3 E AWS ERNiCrMO - 4 SOLDADOS PELO PROCESSO MIG/MAG DUPLO ARAME*
}

\section{Resumo}

Kamilla Giló Santiago ${ }^{1}$ Marcelo Ferreira Motta² Cleiton Carvalho Silva² Jamil Nobre de Castro ${ }^{3}$ Igor Paulino Fernandes ${ }^{3}$

Nesse trabalho para caracterização metalúrgica dos revestimentos compostos pela mistura das ligas AWS ERNiCrMo - 3 E AWS ERNiCrMo - 4 soldados pelo processo MIG/MAG duplo arame foram realizadas análises micrográficas por meio de microscopia eletrônica de varredura. Observou-se semelhança entre os precipitados do topo e da interface do metal de solda com o substrato e que a microestrutura obtida com a soldagem das duas ligas, simultaneamente, resultou na mistura das microestruturas, obtidas a partir das soldagens com cada uma das ligas de forma isolada. $O$ ensaio para avaliação do desempenho da mistura quanto à resistência a corrosão foi realizado conforme a norma ASTM - G 48, método C para determinação da temperatura crítica de pite da mistura das ligas. Foram utilizadas amostras dos revestimentos com maior e menor diluição. O resultado do ensaio apontou que os revestimentos soldados apresentaram temperatura crítica de pite superior ao da liga AWS ERNiCrMo-3 e semelhante ao da liga AWS ERNiCrMo-4.

Palavras-chave: Superligas de níquel; Corrosão.

\section{MICROSTRUCTURAL AND CORROSION CHARACTERIZATION OF THE WELDING OVERLAY THE MIX THE ALLOYS AWS ERNiCrMo - 3 E AWS ERNiCrMo - 4 WITH MIG/MAG DOUBLE WIRE}

\begin{abstract}
In this work for metallurgical characterization of welding overlays composed by the mixture of alloys ERNiCrMo AWS-3 and AWS ERNiCrMo-4 welded by MIG / MAG double wire process, micrographic analyzes were performed by means of scanning electron microscopy (SEM). Similarity was observed between the precipitates at the top of the weld metal and in the interface with the substrate. The microstructure obtained by welding two alloys of both resulted in a mixture of microstructures obtained from welds with each alloy isolation. The test for evaluating the performance of the mixture for resistance to corrosion was performed according to ASTM - G 48, C method to determine the critical pitting temperature of the mixture of alloys. Samples of coatings with higher and lower dilution were used. The test result showed that the welded coating had higher critical pitting temperature than the alloy AWS ERNiCrMo-3 and similar to Alloy AWS ERNiCrMo-4

Keywords: Superalloys based nickel; Corrosion.

1 Engenheira de produção mecânica, mestre, doutoranda, departamento de engenharia metalúrgica e de materiais, Universidade Federal do Ceará (UFC), Fortaleza, CE, Brasil.

2 Engenheiro mecânico, doutor, professor, departamento de engenharia metalúrgica e de materiais, UFC, Fortaleza, Ceará, Brasil.

3 Engenheiro metalurgista, graduando, departamento de engenharia metalúrgica e de materiais, Universidade Federal do Ceará, Fortaleza, Ceará, Brasil.

4 Engenheiro metalurgista, graduado, Universidade Federal do Ceará, Fortaleza, Ceará, Brasil.
\end{abstract}

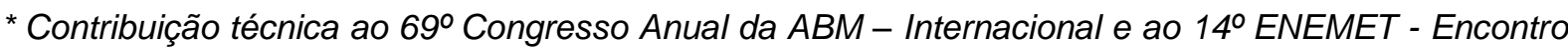
Nacional de Estudantes de Engenharia Metalúrgica, de Materiais e de Minas, 21 a 25 de julho de 2014, São Paulo, SP, Brasil.
} 


\section{INTRODUÇÃO}

O desenvolvimento da soldagem de revestimentos com superligas de níquel tem ganhado forte impulso nos últimos anos, graças aos investimentos oriundos do setor petróleo e gás, tendo em vista os enormes benefícios que podem ser alcançados com o uso destas ligas, ampliando consideravelmente a durabilidade e a confiabilidade dos dutos e equipamentos em operações offshore, notadamente aquelas destinadas à exploração dos campos do pré-sal.

Atualmente, existem projetos de pesquisa em desenvolvimento estudando a soldagem de revestimentos com superligas, os quais são de interesse direto da Petrobras, com foco na exploração da camada pré-sal e no refino do petróleo oriundo destes campos [1-3]. No entanto, investigações sobre alguns aspectos da soldagem destas ligas que ainda não foram contemplados em estudos específicos, mostraram ser importantes e necessários ao desenvolvimento destas soldas.

Estudos recentes sobre soldagem dissimilar, empregando como metal de adição as ligas de níquel AWS ERNiCrMo - 3 e AWS ERNiCrMo - 4, mostraram que essas ligas, comercialmente conhecida respectivamente por,Inconel 625 e Hastelloy C276, por apresentarem diferentes composições químicas, variando em concentrações de $\mathrm{Cr}$, Mo, $\mathrm{Fe}, \mathrm{Nb}$ e $\mathrm{W}$, possuem características microestruturais, propriedades mecânicas, mecanismos de ataque corrosivo e a própria resistência à corrosão, completamente diferentes, identificando-se pontos positivos e negativos em cada liga.

A microestrutura global de revestimentos depositados com a liga Hastelloy C276 é constituída por uma matriz $\vee$ e precipitados interdendríticos e intergranulares, identificando a presença das fases $p, \mu$ e $\sigma$. Silva [1] explica que o teor de cromo de $16 \%$, teor de Mo de $16 \%$ em peso, além da adição de $4 \%$ de W, apresentados nessa liga resulta na segregação do Mo e do W, considerado fator decisivo para as alterações microestruturais observadas.

As microestruturas dos revestimentos das ligas Inconel 625, foram formadas por uma matriz $y$ e fases secundárias de morfologias variadas precipitadas tanto na região intercelular como nas regiões interdendríticas. Principais precipitados encontrados: compostos por $\mathrm{Ni}, \mathrm{Cr}$, Mo e principalmente $\mathrm{Nb}$, aprisionados tanto no centro como entre as dendritas e também nos contornos de grãos. Também foi destacada a ocorrência de carbonetos ou carbonitretros contendo Titânio [1]. A partir do estudo da solidificação da liga 625 foi identificado a presença de carbonetos MC com morfologia eutética [4].

A soldagem MIG/MAG com dois arames é uma variante do processo MIG/MAG convencional e caracteriza-se pela abertura de um par de arcos elétricos entre uma única poça metálica e dois eletrodos consumíveis. Os arcos e a poça fundida são protegidos por um gás que, em conjunto com os eletrodos, é definido pelo tipo de metal de base [5]. Dentre as características principais da versão MIG/MAG com duplo arame Groeteleaars [6], Motta [5] e Ueyma et. al [7] mencionam a possibilidade de atingir elevadas taxas de fusão absolutas, por meio da utilização de altas densidades de corrente, redução do aporte térmico sobre a peça, em virtude das soldagens com velocidades de deslocamento bem superiores que o MIG/MAG com único arame.

Baseado nestas informações surgiu o interesse por se estudar a possibilidade de misturar as ligas Inconel 625 com Hastelloy C276 durante a soldagem com a adição dos dois arames ao mesmo tempo na poça de metal líquido, produzindo uma nova liga. A finalidade é tentar aliar os benefícios de cada uma das ligas, produzindo

\footnotetext{
* Contribuição técnica ao $69^{\circ}$ Congresso Anual da ABM - Internacional e ao 14ํㅡㄹ ENEMET - Encontro Nacional de Estudantes de Engenharia Metalúrgica, de Materiais e de Minas, 21 a 25 de julho de 2014, São Paulo, SP, Brasil.
} 


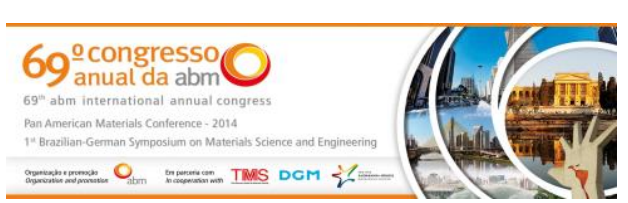

revestimentos com maior resistência à corrosão se comparada às ligas individualmente, além de tentar minimizar os efeitos deletérios que as alterações metalúrgicas causam a cada uma das ligas.

Desse modo, o trabalho tem como objetivo identificar as possíveis microestruturas formadas e identificar a temperatura crítica de pite para essa nova liga resultante da mistura das ligas de níquel AWS ER NiCrMo-3 e AWS ER NiCrMo-4.

\section{MATERIAIS E MÉTODOS}

\subsection{Equipamentos}

Para soldagem dos revestimentos foi utilizado um robô industrial para deslocamento automático da tocha de soldagem com incerteza de $\pm 0,1 \mathrm{~mm}$ no posicionamento, uma fonte de soldagem eletrônica multiprocesso com corrente máxima de $550 \mathrm{~A}$, uma fonte DIGlplus A7 450, dois sistemas de aquisição de dados para adquirir os sinais de tensão, corrente, comprimento do arame consumido, tempo de arco aberto, dois sistemas tracionadores de arame.

$\mathrm{Na}$ caracterização microestrutural do resvestimento foi utilizada uma fonte de corrente contínua para ataque eletrolítico, o microscópio eletrônico de varredura (MEV) com dispositivo para microanálise química por espectroscopia por dispersão de energia raios- $X$ (EDS).

Os ensaios de Corrosão foram realizados segundo a Norma ASTM G-48, utilizando banho ultratermostático, cloreto de Ferro; ácido clorídrico; béquer; e placas de vidro

\subsection{Material de Consumo}

A composição dos materiais a serem utilizados é apresentada na Tabela 1, com diâmetro de $1,14 \mathrm{~mm}$, o gás de proteção utilizado foi argônio puro.com vazão mantida em $22 \mathrm{l} / \mathrm{min}$.

Tabela 1. Composição química dos metais de adição

\begin{tabular}{c|c|c|c|c|c|c|c|c}
\hline Material & \multicolumn{7}{c}{ Composição química (\% em peso) } \\
\hline \multirow{2}{*}{$\begin{array}{c}\text { ERNiCrMo } \\
\text { (INCONEL } \\
625)\end{array}$} & $\mathrm{Ni}$ & $\mathrm{Cr}$ & $\mathrm{Mo}$ & $\mathrm{C}$ & $\mathrm{Fe}$ & $\mathrm{Cu}$ & $\mathrm{Al}$ & $\mathrm{Ti}$ \\
\cline { 2 - 10 } & 64,09 & 22,73 & 8,75 & 0,01 & 0,35 & 0,01 & 0,17 & 0,19 \\
\cline { 2 - 10 } & $\mathrm{Nb}+\mathrm{Ta}$ & $\mathrm{Si}$ & $\mathrm{Mn}$ & $\mathrm{P}$ & $\mathrm{S}$ & Outros & & \\
\cline { 2 - 10 } & 3,53 & 0,04 & 0,10 & 0,002 & 0,001 & $<0,50$ & & \\
\hline $\begin{array}{c}\text { ERNiCrMo -4 } \\
\text { (HASTELLOY } \\
\text { C-276) }\end{array}$ & $\mathrm{Ni}$ & $\mathrm{Cr}$ & $\mathrm{Mo}$ & $\mathrm{C}$ & $\mathrm{Fe}$ & $\mathrm{Cu}$ & $\mathrm{Co}$ & $\mathrm{Mn}$ \\
\cline { 2 - 10 } & 59,56 & 15,97 & 15,24 & 0,002 & 5,12 & 0,08 & 0,04 & 0,38 \\
\cline { 2 - 10 } & $\mathrm{Si}$ & $\mathrm{P}$ & $\mathrm{S}$ & $\mathrm{W}$ & $\mathrm{V}$ & Outros & & \\
\hline
\end{tabular}

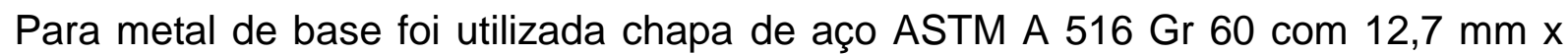
$150 \mathrm{~mm} \times 200 \mathrm{~mm}$, esse material foi escolhido por ser empregado na construção de equipamentos e na indústria do petróleo e gás natural, com a composição mostrada na Tabela 2.

Tabela 2. Composição química do metal de base

\begin{tabular}{l|l|l|l|l|l|l|l|l}
\hline \multicolumn{1}{c|}{ Material } & \multicolumn{7}{c}{ Composição (\% em peso) } \\
\hline $\begin{array}{l}\text { ASTM A516 Gr } \\
60\end{array}$ & $\mathrm{Ni}$ & $\mathrm{C}$ & $\mathrm{Cr}$ & Mo & $\mathrm{Fe}$ & $\mathrm{Al}$ & $\mathrm{Mn}$ & $\mathrm{Si}$ \\
\cline { 2 - 10 } & 0,01 & 0,15 & 0,02 & 0,01 & Bal. & 0,02 & 0,95 & 0,2 \\
\hline
\end{tabular}

* Contribuição técnica ao 69 Congresso Anual da ABM - Internacional e ao 14ํㅡㄹ ENEMET - Encontro Nacional de Estudantes de Engenharia Metalúrgica, de Materiais e de Minas, 21 a 25 de julho de 2014, São Paulo, SP, Brasil. 


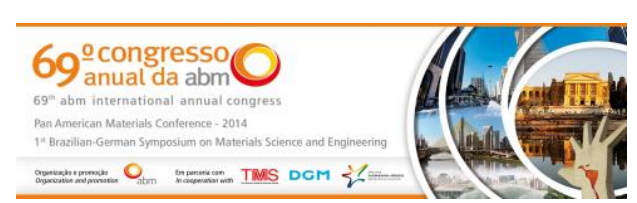

\subsection{Metodologia}

Os revestimentos foram soldados utilizando energia balanceada, somando 7,56 $\mathrm{KJ} / \mathrm{mm}$, a fonte operou no modo corrente constante pulsado sem defasagem entre as correntes, cujos valores de pulso encontram-se na Tabela 3.

Tabela 3. Parâmetros de pulso utilizado para soldagem dos revestimentos

\begin{tabular}{ccccccc}
\hline \multirow{2}{*}{ Energia } & $\mathbf{I m}$ & $\mathbf{I p}$ & $\mathbf{T p}$ & $\mathbf{F p}$ & $\mathbf{t b}$ & $\mathbf{l b}$ \\
\cline { 2 - 7 } & 180 & 400 & 2 & 100 & 8 & 125 \\
\hline
\end{tabular}

A velocidade de soldagem foi $100 \mathrm{~cm} / \mathrm{min}$, e os eletrodos foram posicionados um atrás do outro em relação à velocidade de soldagem, a tocha deslocou-se realizando tecimento triangular. Para as soldagens dos revestimentos variou-se o ângulo de ataque da tocha, ângulo formado entre a tocha e a normal ao metal de base, e sobreposição. O primeiro assumiu $10^{\circ}, 15^{\circ}$ e $28^{\circ}$, enquanto que a sobreposição de passes foi feita deslocando-se a tocha de $50 \%, 60 \%$ e $70 \%$ da largura do cordão, com o intuito de se obter redução nos valores de diluição e evitar defeitos no pé do cordão, conforme vista na Tabela 4.

Tabela 4. Parâmetros de soldagem dos revestimentos

\begin{tabular}{lcc}
\hline \multicolumn{1}{c}{ Ensaio } & Ângulo & Sobreposição \\
\hline Revestimento A & $28^{\circ}$ & $50 \%$ \\
\hline Revestimento B & $28^{\circ}$ & $30 \%$ \\
\hline Revestimento C & $28^{\circ}$ & $40 \%$ \\
\hline Revestimento D & $10^{\circ}$ & $30 \%$ \\
\hline Revestimento E & $10^{\circ}$ & $40 \%$ \\
\hline Revestimento F & $10^{\circ}$ & $50 \%$ \\
\hline Revestimento G & $15^{\circ}$ & $50 \%$ \\
\hline Revestimento H & $15^{\circ}$ & $40 \%$ \\
\hline Revestimento I & $15^{\circ}$ & $30 \%$ \\
\hline
\end{tabular}

A caracterização metalúrgica foi realizada por meio de microscopia eletrônica de varredura, afim de, se visualizar as microfases presentes. A amostra foi retirada da seção transversal do revestimento de menor diluição, pois esse atendia a segunda categoria da norma ISO 1043, FE10, que indica que o teor de ferro máximo no metal de solda pode ser igual ou inferior 10\%, contemplando também o valor de espessura mínima indicado para construção de vaso de pressão revestidos por solda que é de $3 \mathrm{~mm}$.

A preparação consistiu de lixamento até a granulação de 1200 e polimento mecânico com pasta de diamante até $1 / 4 \mu \mathrm{m}$. Foi realizado ataque por imersão no metal de base utilizando reagente Nital $3 \%$. Já no metal de solda foi realizado ataque eletroquímico com solução contendo $10 \%$ de ácido crômico diluído em água deionizada (\% em peso) utilizando tensão de $2,5 \mathrm{~V}$ e 20 segundos.

O ensaio para avaliação do desempenho quanto à resistência a corrosão foi realizado conforme a norma ASTM - G 48, método C. Foram utilizados corpos de provas com dimensões de $20 \mathrm{~mm} \times 40 \mathrm{~mm}$, com espessura variada, de acordo com o reforço da amostra. Utilizou-se amostras dos revestimentos com maior e menor diluição, a fim de se observar a influência desse fator na resistência a corrosão por

\footnotetext{
* Contribuição técnica ao $69^{\circ}$ Congresso Anual da ABM - Internacional e ao 14ํㅡㄹ ENEMET - Encontro Nacional de Estudantes de Engenharia Metalúrgica, de Materiais e de Minas, 21 a 25 de julho de 2014, São Paulo, SP, Brasil.
} 
pite do revestimento. A temperatura inicial dos ensaios foi de $50^{\circ} \mathrm{C}$, acrescidas de $5^{\circ} \mathrm{C}$ entre os ensaios.

\section{RESULTADOS E DISCUSSÃO}

Em relação ao aspecto superficial, os revestimentos tiveram aspectos semelhantes de acabamentos, conforme imagens mostradas na Figura 1.
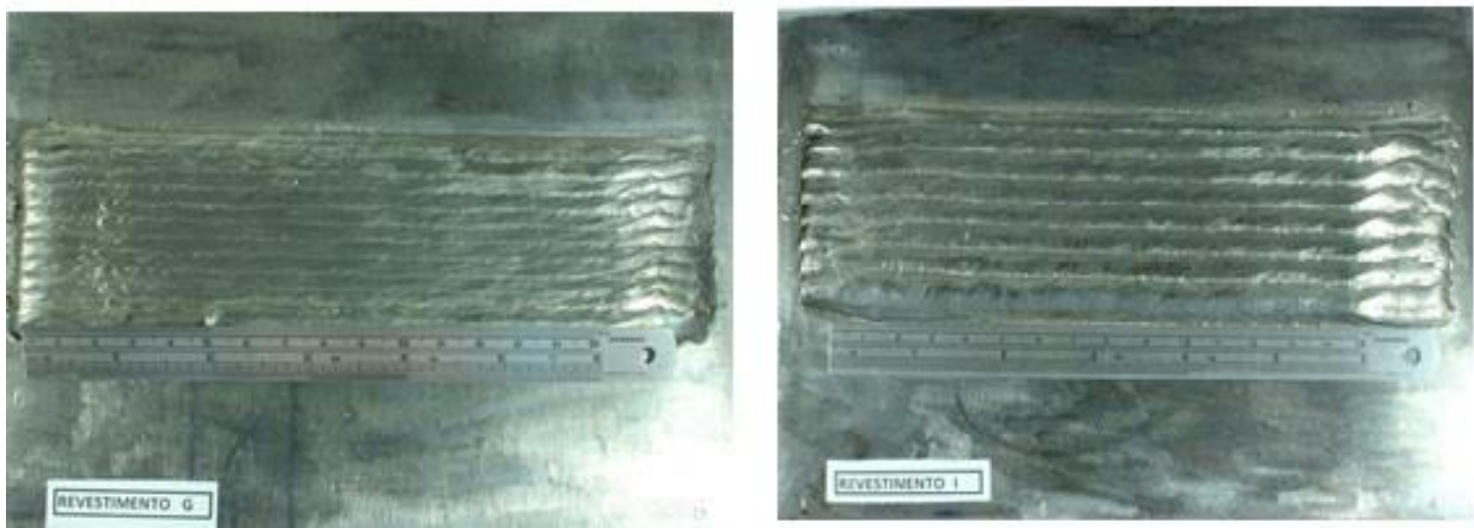

Figura 1. Aspectos superficiais do revestimento

Para análise geométrica foram consideradas duas seções transversais dos revestimentos: à aproximadamente $30 \mathrm{~mm}$ do início e a $30 \mathrm{~mm}$ do final. Ao longo de cada seção, foram medidos três valores de reforço e a diluição, os valores obtidos encontram-se na Tabela 5.

Tabela 5. Características geométricas dos revestimentos

\begin{tabular}{c|c|c|c|c}
\hline Ensaio & Reforço 1 & Reforço 2 & Reforço 3 & Diluição \\
\hline \multirow{2}{*}{ Revestimento A } & 2,6616 & 3,3333 & 3,9801 & $10,28 \%$ \\
\cline { 2 - 5 } & 3,1351 & 2,9189 & 3,8378 & $11,77 \%$ \\
\hline \multirow{2}{*}{ Revestimento B } & 2,1978 & 2,5274 & 3,0219 & $16,92 \%$ \\
\cline { 2 - 5 } & 2,0879 & 2,6699 & 2,864 & $17,34 \%$ \\
\hline \multirow{2}{*}{ Revestimento C } & 3,2894 & 3,5868 & 3,75 & $11,88 \%$ \\
\cline { 2 - 5 } & 1,8264 & 2,9333 & 3,26 & $16,72 \%$ \\
\hline \multirow{2}{*}{ Revestimento D } & 2,2222 & 2,8352 & 3,4099 & $17,99 \%$ \\
\cline { 2 - 5 } & 2,39 & 2,9343 & 2,8978 & $23,09 \%$ \\
\hline \multirow{2}{*}{ Revestimento E } & 2,9934 & 3,5552 & 3,8815 & $13,07 \%$ \\
\cline { 2 - 5 } & 3,1828 & 3,44 & 3,858 & $13,41 \%$ \\
\hline \multirow{2}{*}{ Revestimento F } & 3,5632 & 3,908 & 4,0996 & $10,85 \%$ \\
\cline { 2 - 5 } & 3,4844 & 4,3205 & 4,1114 & $10,13 \%$ \\
\hline Revestimento G & 3,9202 & 4,2524 & 3,9867 & $9,75 \%$ \\
\cline { 2 - 5 } & 4,086 & 4,1935 & 4,301 & $9,67 \%$ \\
\hline Revestimento H & 2,7952 & 3,3464 & 3,5433 & $13,41 \%$ \\
\cline { 2 - 5 } & 2,9729 & 3,2432 & 3,3204 & $14,44 \%$ \\
\hline Revestimento I & 2,391304 & 2,427536 & 2,4637 & $22,57 \%$ \\
\cline { 2 - 5 } & 2,1454 & 2,3272 & 3,0181 & $20,64 \%$ \\
\hline
\end{tabular}

\footnotetext{
* Contribuição técnica ao 69ำ Congresso Anual da ABM - Internacional e ao 14ํㅡㄹ ENEMET - Encontro Nacional de Estudantes de Engenharia Metalúrgica, de Materiais e de Minas, 21 a 25 de julho de 2014, São Paulo, SP, Brasil.
} 


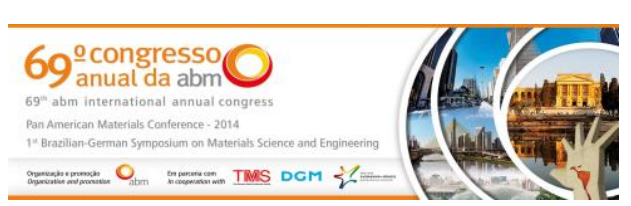

Dentre os valores medidos de diluição destacam-se os referentes aos revestimentos G, apresentando as menores diluições e os revestimentos I, apresentando maiores diluições, conforme pode ser verificado nas secções transversais visualizadas na Figura 2.
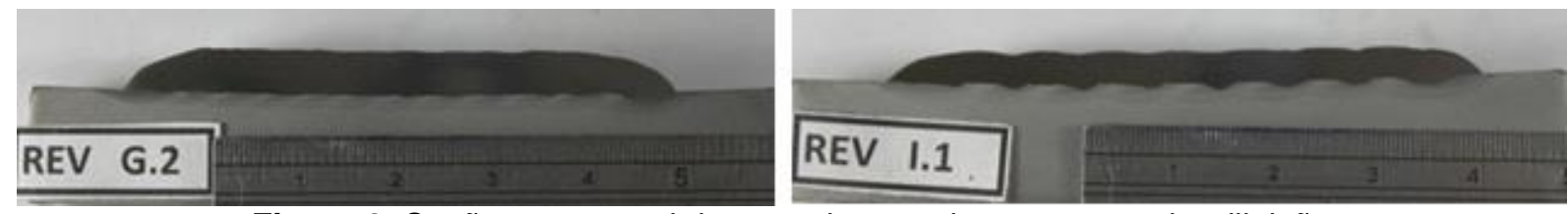

Figura 2. Seção transversal do revestimento de menor e maior diluição

Utilizando o método ANOVA, de análise de variância, observou-se que somente a sobreposição teve efeito estatisticamente significativo tanto na diluição, como no reforço, como se verifica na Tabela 6.

Tabela 6. Valores de significâncias para os parâmetros de revestimento

\begin{tabular}{l|c|c}
\hline & Diluição & Reforço \\
\hline Ângulo & 0,550013 & 0,084765 \\
\hline Sobreposição & $\underline{0,000038}$ & $\underline{0,001070}$ \\
\hline Ângulo e sobreposição & 0,292769 & 0,429006 \\
\hline
\end{tabular}

Esse resultado, provavelmente pode ser creditado ao fato de que, das três condições de sobreposição utilizadas, na condição de $50 \%$ de sobreposição o arco incidia menos no metal de base, reduzindo o aporte de energia direcionado ao substrato, e também sua participação na zona fundida. A Figura 3 mostra a redução da diluição nas soldagens com $50 \%$ de sobreposição e ainda os maiores valores de reforço também para essa condição.
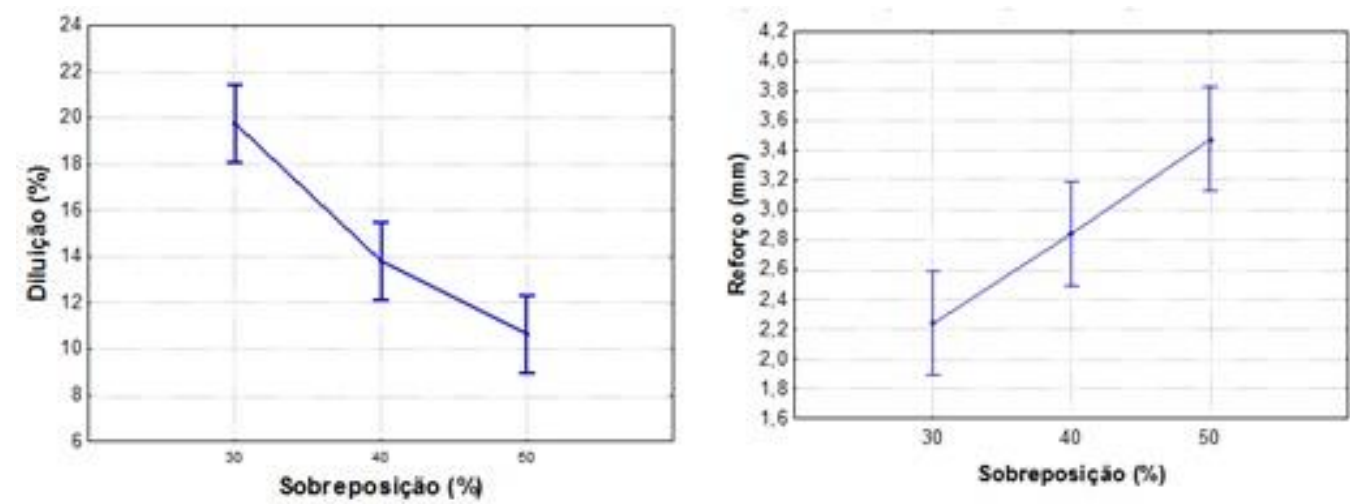

Figura 3. Variação da diluição e do reforço na soldagem dos revestimentos

Nessa condição, o arco deve ser deslocado de uma distância de 50\% da largura do primeiro cordão, o que resulta em aumentos progressivos do reforço do revestimento, pois o metal é depositado em cima do cordão anterior. Resultado semelhante foi verificado por Aguiar [2] na soldagem de revestimento com processo MIG/MAG. O autor destaca que o aumento no reforço em direção ao fim do revestimento, verificado na seção transversal, deve-se ao efeito da sobreposição dos cordões de solda que vai se somando à medida que o revestimento vai avançando.

\footnotetext{
* Contribuição técnica ao $69^{\circ}$ Congresso Anual da ABM - Internacional e ao 14ํㅡㄹ ENEMET - Encontro Nacional de Estudantes de Engenharia Metalúrgica, de Materiais e de Minas, 21 a 25 de julho de 2014, São Paulo, SP, Brasil.
} 


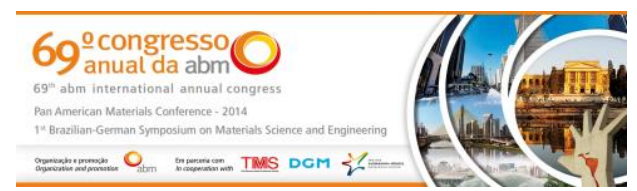

\subsection{Caracterização Metalúrgica do Revestimento}

A análise das microestruturas apresentadas foi realizada no revestimento $G$, o qual apresentou menor diluição. A caracterização microestrutural foi feita ao longo de uma varredura no primeiro cordão do revestimento, conforme marcado na Figura 4, sendo essa a região que sofreu um maior efeito dos ciclos térmicos da soldagem dos demais cordões. A região 01 corresponde à interface entre metal de solda e metal de base e a região 02 ao metal de solda. Foram levantadas as composições químicas da matriz austenítica, bem como, dos precipitados encontrados nessas regiões.

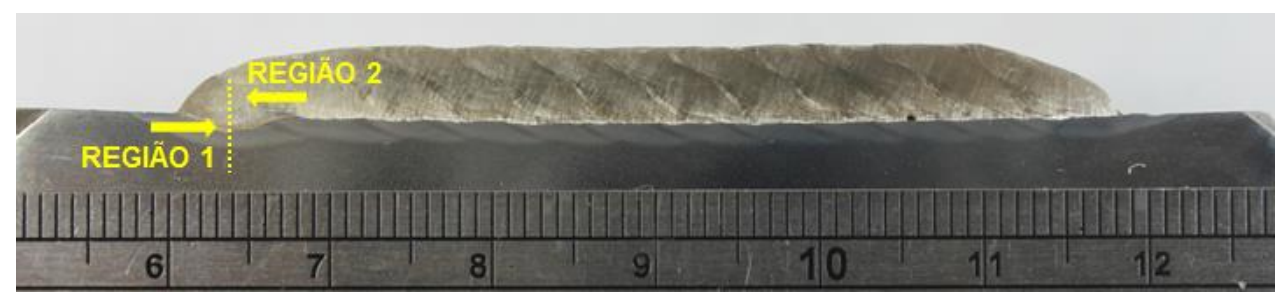

Figura 4. Corpo de provo usado para análise microestrutural

Observou-se a presença de um precipitado rico em $\mathrm{Nb}$ e Ti observado na Figura 5 e sua composição é apresentada no ponto P4 (coluna 03) da Tabela 7. Esses resultados são semelhantes aos encontrados por Aguiar [2] e Silva [1] nas soldagens com ligas AWS ERNiCrMo-3. Os autores explicam que a menor solubilidade do $\mathrm{Nb}$, Si e Mo no sólido, que os elementos $\mathrm{Fe}$, $\mathrm{Ni}$ e $\mathrm{Cr}$, tendem a segregar mais fortemente, prevendo a participação desses elementos em fases secundárias.

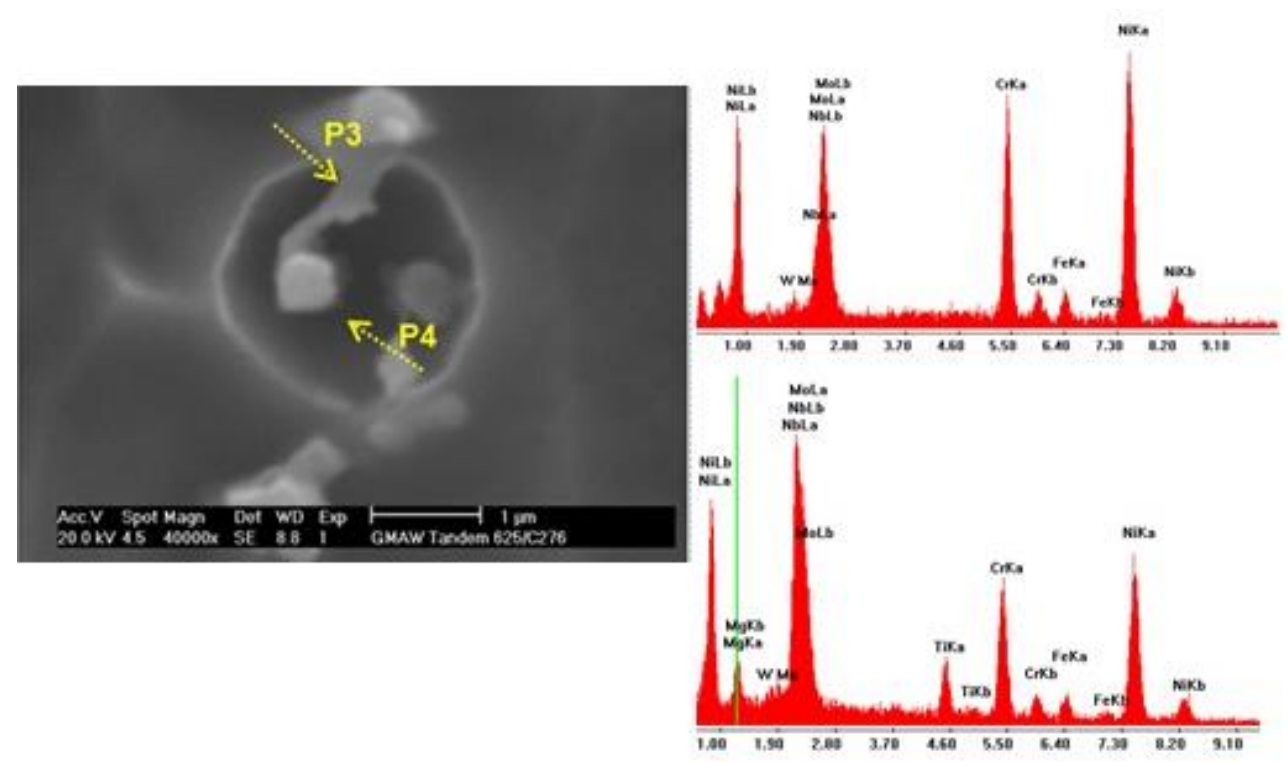

Figura 5. Imagem de MEV do precipitado B e sua composição química por EBS dos pontos indicados

O precipitado $\mathrm{C}$, visualizado na Figura 6 possui alto teor de $\mathrm{W}$ e Mo, verificado nos pontos P5 e P6 (colunas 4 e 5) da Tabela 7, características semelhantes aos precipitados encontrados por Aguiar [2] e Silva[1] nas soldagens realizadas com a liga AWS ER NiCrMo-4, isso em virtude desses elementos apresentarem menor

\footnotetext{
* Contribuição técnica ao $69^{\circ}$ Congresso Anual da ABM - Internacional e ao 14ํㅡㄹ ENEMET - Encontro Nacional de Estudantes de Engenharia Metalúrgica, de Materiais e de Minas, 21 a 25 de julho de 2014, São Paulo, SP, Brasil.
} 

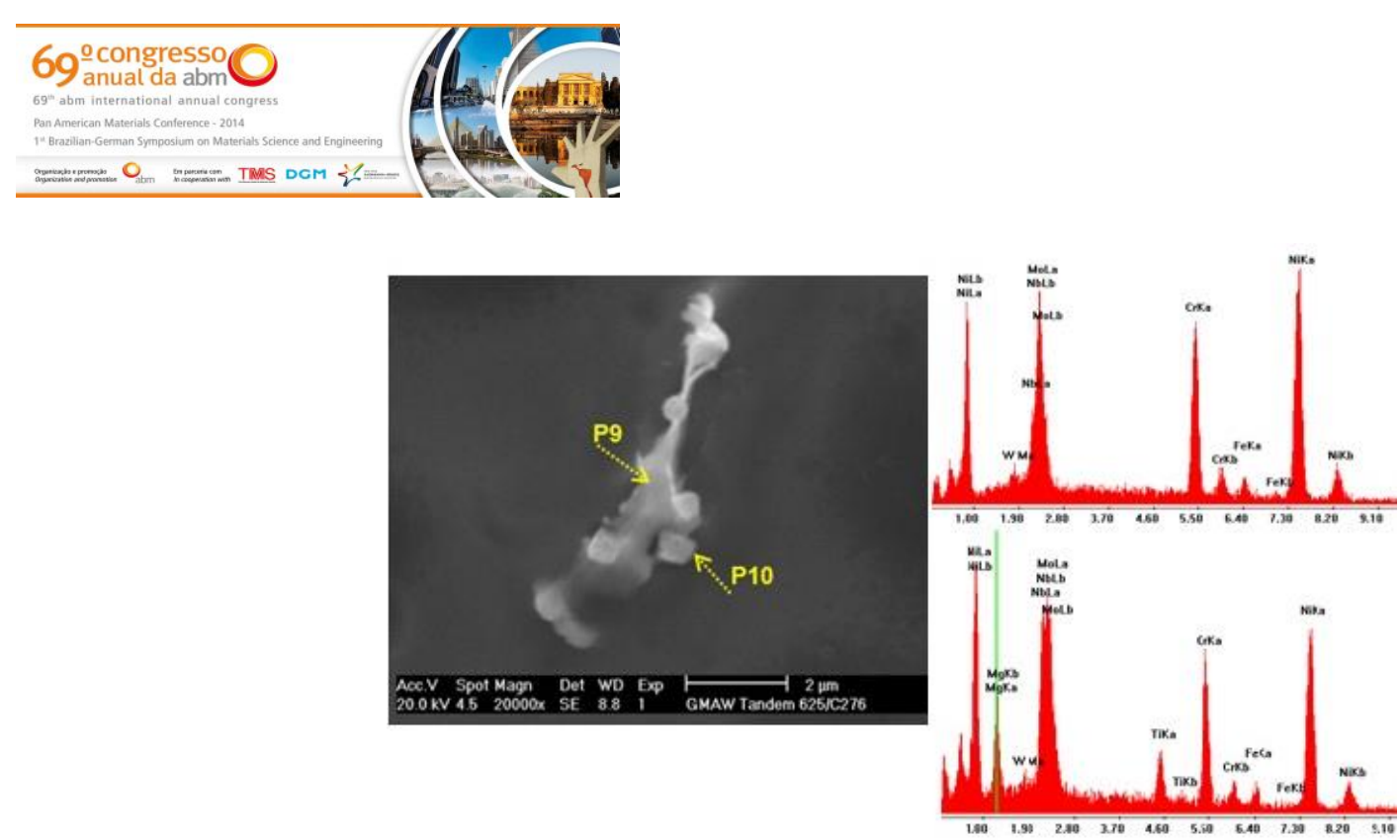

Figura 7. Imagens do MEV do precipitado E e sua a composição química por EBS dos pontos indicados

Em relação ao precipitado $\mathrm{F}$, localizado na região interdendrítica conforme a Figura 8, possui elevado teores de W e Mo. conforme a composição química exibida para P11 e P12 na Tabela 8. Estima-se que esse precipitado possa corresponder a uma fase $P$ ou $\mu$. Nas soldagens realizadas com a liga AWS ERNiCrMo-4, Silva [1], após ensaios de difração de raio- $X$, identificou a fase $P$ como principal fase secundária encontrada.

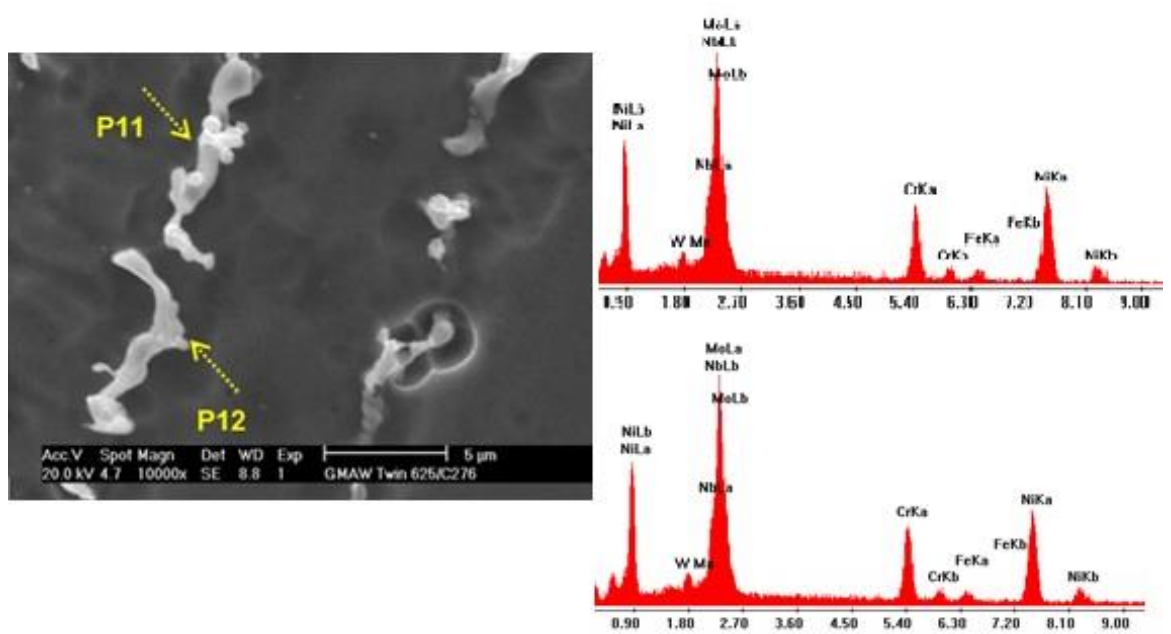

Figura 8. Imagem de MEV do precipitado F e sua composição química por EBS dos pontos indicados

Tabela 8. Composição química dos precipitados encontrados no metal de solda

\begin{tabular}{c|c|c|c|c}
\hline & \multicolumn{2}{|c|}{$\mathrm{P}$} & \multicolumn{2}{c}{$\mathrm{F}$} \\
\hline & $\mathrm{P} 9$ & $\mathrm{P} 10$ & $\mathrm{P} 11$ & $\mathrm{P} 12$ \\
\hline $\mathrm{Ni}$ & 50,57 & 37,58 & 33,25 & 39,59 \\
\hline $\mathrm{Cr}$ & 17,56 & 14,04 & 13,84 & 15,52 \\
\hline $\mathrm{Mo}$ & 20,45 & 15,17 & 35,74 & 30,45 \\
\hline $\mathrm{Nb}$ & 6,5 & 17,97 & 10,71 & 6,34 \\
\hline $\mathrm{Ti}$ & & 3,81 & & \\
\hline $\mathrm{Fe}$ & 2,48 & 2,47 & 1,78 & 3,26 \\
\hline $\mathrm{W}$ & 2,43 & 1,56 & 4,68 & 4,85 \\
\hline $\mathrm{Mg}$ & \multicolumn{3}{|l}{}
\end{tabular}

\footnotetext{
* Contribuição técnica ao 69ํ Congresso Anual da ABM - Internacional e ao 14ํㅡㄹ ENEMET - Encontro Nacional de Estudantes de Engenharia Metalúrgica, de Materiais e de Minas, 21 a 25 de julho de 2014, São Paulo, SP, Brasil.
} 


\subsection{Comportamento de Resistência a Corrosão por Pite}

Verificou-se durante a preparação das amostras a presença de possíveis defeitos (estruturas de formatos circulares semelhante a poros, porém não localizados entre os cordões dos revestimentos). Para essas amostras foram calculadas perdas de massa maior que $0,0001 \mathrm{~g} / \mathrm{cm}^{2}$ logo na primeira temperatura utilizada, $50^{\circ} \mathrm{C}$.

Os pites se apresentaram discretamente nas amostras, como é possível visualizar na Figura 9, na forma de pequenos pites e alguns metaestáveis invisíveis a olho nu, ficando a perda de massa bem próxima do valor determinado pela norma.
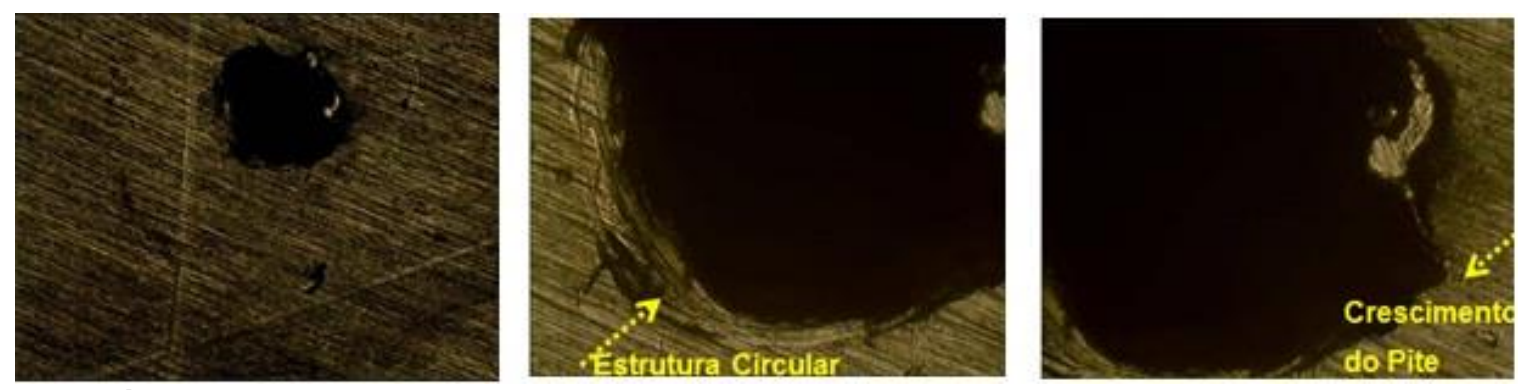

Figura 9. Fotos do pite na amostra de menor diluição e detalhes com aumento de 50x.

A partir da análise das fotos dos pites, encontrados estima-se que possivelmente alguns pites tenham sido nucleados em estruturas circulares, semelhantes a poros, preexistentes nas amostras.

Outras duas amostras, que durante a preparação não apresentaram nenhum defeito, continuaram no ensaio até a temperatura de $75^{\circ} \mathrm{C}$ sem ter apresentado perda de massa, esse comportamento tem sido motivador no que tange o questionamento inicial do trabalho de se obter com a mistura das ligas melhores desempenhos à corrosão. Aguiar [1] encontrou temperatura crítica de pite de $80^{\circ} \mathrm{C}$ para liga AWS ERNiCrMo-4. O fato de duas amostras com diluições extremas continuarem no ensaio de corrosão vai de confronto com Gittos e Gootch [8], que ao realizar o ensaio segundo a norma ASTM-G48 com revestimentos da liga Inconel 625 em aço $\mathrm{C}-\mathrm{Mn}$ encontrou resultados que apontam haver correlação entre a resistência a corrosão por pites e a diluição.

\section{CONCLUSÃO}

A soldagem de revestimentos com sobreposição de $50 \%$ dos cordões e com $15^{\circ}$ de ângulo de ataque, apresentou melhores resultados geométricos menor diluição (>10\%) e maiores reforços (> $3 \mathrm{~mm}$ ), indicando o processo como MIG/MAG com configuração duplo arame, empregando simultaneamente as ligas AWS ERNiCrMo3 e AWS ERNiCrMo-4 como uma boa possibilidade para soldagem de revestimentos em estruturas e equipamentos da indústria de petróleo e gás.A partir das análises feitas ao longo da varredura do primeiro cordão de solda do revestimento, pode-se comentar que tanto próximo à interface, como no metal de solda, as composições químicas obtidas por EDS dos precipitados encontrados não apresentaram grandes disparidades, intuindo-se a concluir que não houve diferenças em relação aos tipos de precipitados formados na interface do cordão e ao longo do metal de solda, observação essa não podendo ser feita em relação à quantificação de fases, pois essa informação não foi explorada. Os precipitados encontrados foram semelhantes aos encontrados nas soldagens realizadas por outros autores [1,2] com as ligas

\footnotetext{
* Contribuição técnica ao $69^{\circ}$ Congresso Anual da ABM - Internacional e ao 14ํㅡㄹ ENEMET - Encontro Nacional de Estudantes de Engenharia Metalúrgica, de Materiais e de Minas, 21 a 25 de julho de 2014, São Paulo, SP, Brasil.
} 


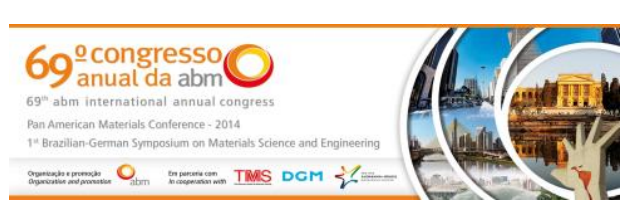

AWS ERNiCrMo-3 AWS ERNiCrMo-4. Assim pela análise realizada entende-se que a microestrutura obtida com a soldagem das duas ligas simultaneamente resulta na mistura das microestruturas obtidas com a soldagem de cada material isolado.

\section{Agradecimentos}

Ao Engesolda - Laboratório de Engenharia de Soldagem da UFC pelo suporte ao desenvolvimento do trabalho. À Capes e CNPQ pelo apoio financeiro.

\section{REFERÊNCIAS}

1 Silva CC. Revestimentos de ligas de níquel depositadas pelo processo tig com alimentação de arame frio - aspectos operacionais e metalúrgicos [tese doutorado]. Fortaleza: Universidade Federal do Ceará; 2010.

2 Aguiar WM. Revestimento por soldagem $\mathrm{mig} / \mathrm{mag}$ empregando ligas de níquel para aplicações em componentes do setor de petróleo e gás natural [tese doutorado]. Fortaleza: Universidade Federal do Ceará; 2010.

3 Magalhães SG. Avaliação do revestimento a base de ligas de ni em aço estrutural com os metais de adição ER NiCrMo-3 e ER NiCrMo-4, através da soldagem mig/mag [dissertação mestrado]. Fortaleza: Universidade Federal do Ceará; 2008.

4 Cieslak MJ, Headley TJ, Knorovsky GA, Romig Jr.AD, Kollie T. A comparison of the solidification behavior of incoloy 909 and inconel 718. Metallurgical transactions A. 1990;214:479-488.

5 Motta MF. Aplicação do processo $\mathrm{mig} / \mathrm{mag}$ pulsado com duplo arame e potenciais isolados em operações de revestimento [tese de doutorado]. Florianópolis: Universidade Federal de Santa Catarina; 2002.

6 Groetelaars PJ, Morais CO, Scotti A. Influência do comprimento do arco sobre a transferência metálica no processo $\mathrm{mig} / \mathrm{mag}$ duplo-arame com potencial único. In: Anais do III congresso brasileiro de engenharia de fabricação - COBEF; 2005; Joinville, Brasil. Joinville: ABCM; 2005.

7 Ueyama T, Ohnawa T, Tanaka M, Nakata K. Effects of torch configuration and welding current on weld bead formation in high speed tandem pulsed gas metal arc welding of steel sheets. Science and technology of welding and joining. 2005;10(6):750-759.

8 Gittos MF, Gooch G. Effect of iron diluition corrosion resistance of Ni-Cr-Mo alloy cladding. British corrosion journal. 1996;31:309-314.

\footnotetext{
* Contribuição técnica ao $69^{\circ}$ Congresso Anual da ABM - Internacional e ao 14ํㅡㄹ ENEMET - Encontro Nacional de Estudantes de Engenharia Metalúrgica, de Materiais e de Minas, 21 a 25 de julho de 2014, São Paulo, SP, Brasil.
} 